\title{
DEVICES
}

\section{Novel uses of the Rashkind ductal umbrella in adults and children with congenital heart disease}

\author{
Andrew N Redington, Michael L Rigby
}

\begin{abstract}
Objective-To show possible alternative uses of the Rashkind ductal umbrella.

Design-Descriptive study of selected, non-randomised patients; with specific congenital heart lesions other than an arterial duct.
\end{abstract}

Setting-A tertiary referral centre.

Patients-Nine patients with congenital heart lesions; four with interatrial communications after a fenestrated Fontan procedure two with large aortopulmonary collaterals, three with an unoperated ventricular septal defect.

Interventions-Placement of a Rashkind umbrella occluder as treatment for a haemodynamically important lesion.

Results-Successful placement with symptomatic and haemodynamic improvement in all.

Conclusions-The Rashkind ductal umbrella may be used successfully to treat some patients with aortopulmonary collateral vessels, ventricular septal defects, and interatrial communications after the fenestrated Fontan procedure.

\section{(Br Heart J 1993;69:47-51)}

Transcatheter occlusion of the arterial duct with a Rashkind umbrella is now a routine procedure in many units. The same technology has been applied to the development of the Lock clamshell device which has been successfully used to close atrial septal defects, both congenital $^{1}$ and iatrogenic, ${ }^{2}$ and also unoperated muscular ventricular septal defects. ${ }^{3}$ The clamshell device is not yet available for general use outside North America.

In this report we describe the successful adaptation and use of the Rashkind duct occluder in the management of conditions other than the arterial duct.

Department of

Paediatric Cardiology, Royal Brompton

National Heart and

Lung Hospital, London

A N Redington

M L Rigby

Correspondence to

Dr A N Redington, Royal Brompton National Heart and Lung Hospital, Sydney Street, London SW3 $6 \mathrm{NP}$

Accepted for publication 22 June 1992.

\section{Case reports}

Nine patients underwent 11 procedures. In each case it was considered that umbrella occlusion was preferable to surgery for the particular lesion. They were selected examples and not part of a research protocol. As such, their treatment was individual, and umbrella placement was only performed after full discussion with the patient or parents, and with written informed consent.



A

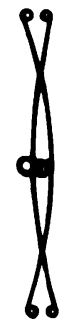

$B$
Figure 1 Effect of placing a gentle bend in each of the arms of the $17 \mathrm{~mm}$ Rashkind double umbrella device (before, $A ;$ after, $B$ ).

CASES 1-4: CLOSURE OF ATRIAL SEPTAL DEFECTS (FENESTRATED FONTAN PROCEDURE)

An eight year old boy was referred from another hospital for further management. He had previously undergone right and left Blalock-Taussig shunts and a central aortopulmonary shunt. Echocardiography confirmed the diagnosis of situs solitus with a concordant atrioventricular and ventriculoarterial connection. There was valvar pulmonary atresia with a hypoplastic tricuspid valve and diminutive right ventricle, and a small muscular ventricular septal defect. The risk factors for Fontan operation were (a) small confluent pulmonary arteries (McGoon ratio $1 \cdot 5: 1)$; (b) origin stenosis of the left pulmonary artery; and

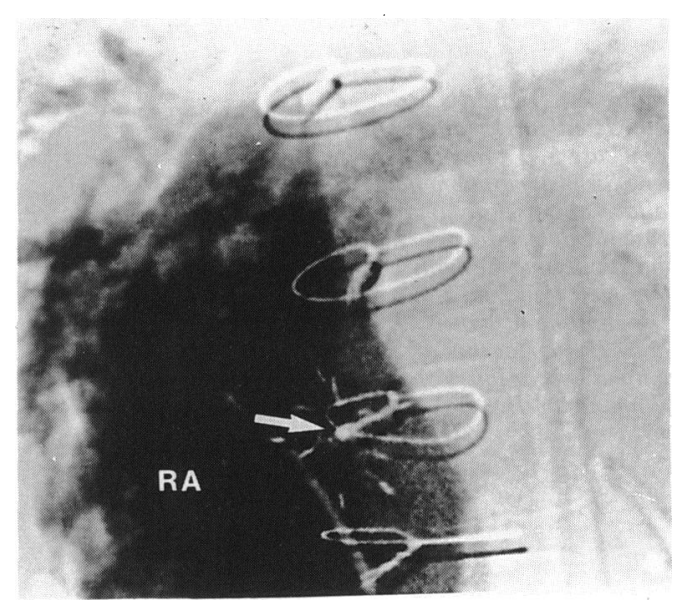

Figure 2 Digitally subtracted image of a right atrial angiogram after trimming placement of a modified $17 \mathrm{~mm}$ umbrella device in the deliberately fenestrated atrial septum (marked with arrow). There is complete occlusion. $R A$, right atrium. 
Table 1 Details of closure of iatrogenic atrial septal defect after the fenestrated Fontan procedure

\begin{tabular}{|c|c|c|c|c|c|c|c|c|}
\hline Patient & Age & Diagnosis & $\begin{array}{l}\text { Procedure } \\
\text { (fenestration) }\end{array}$ & $\begin{array}{l}R A P \\
\text { (before) }\end{array}$ & $\begin{array}{l}R A P \\
\text { (after) }\end{array}$ & $\begin{array}{l}\mathrm{SAO}_{2} \\
\text { (before) }\end{array}$ & $\begin{array}{l}\mathrm{SAO}_{2} \\
\text { (after) }\end{array}$ & Comments \\
\hline 1 & 8 & PA + IVS, A-P shunts $\times 3$ & $\mathrm{APC}(4 \mathrm{~mm})$ & 11 & 15 & 78 & 94 & $\begin{array}{l}\text { Complete occlusion: residual } \mathrm{R} \rightarrow \mathrm{L} \\
\text { shunt through VSD }\end{array}$ \\
\hline $\begin{array}{l}2 \\
3\end{array}$ & $\begin{array}{r}22 \\
2\end{array}$ & $\begin{array}{l}\text { DILV, SAS, PAB } \\
\text { DORV, HLV, SPS }\end{array}$ & $\begin{array}{l}\text { TCPC }(4 \mathrm{~mm}) \\
\text { TCPC }(3 \mathrm{~mm})\end{array}$ & $\begin{array}{l}12 \\
12\end{array}$ & $\begin{array}{l}14 \\
14\end{array}$ & $\begin{array}{l}85 \\
84\end{array}$ & $\begin{array}{l}97 \\
95\end{array}$ & $\begin{array}{l}\text { Complete occlusion } \\
\text { Complete occlusion: small residual ASD } \\
\text { at suture line }\end{array}$ \\
\hline 4 & 8 & DORV, HLV, SPS, shunts $\times 2$ & TCPC (4 mm) & 11 & 15 & 78 & 98 & Complete occlusion \\
\hline
\end{tabular}

PA + IVS, pulmonary atresia with intact ventricular septum; A-P, aortopulmonary; DILV, double inlet left ventricle; SAS, subaortic stenosis; PAB, pulmonary arterial band; DORV, double outlet right ventricle; HLV, hypoplastic left ventricle; SPS, subpulmonary stenosis; APC, atriopulmonary connection; TCPC, total arterial band; DORV, double outlet right ventricle; $\mathrm{HLV}$, hypoplastic left ventricle; SPS, subpulmonary stenosis; APC, atriopulmonary connection;
cavopulmonary connection; RAP, mean right atrial pressure; $\mathrm{SAO}_{2}$, arterial oxygen saturation; ASD, atrial septal defect; VSD, ventricular septal defect.

(c), a mean pulmonary artery pressure of $19 \mathrm{~mm}$ $\mathrm{Hg}$. A modified Fontan procedure, with anastomosis of the right atrium directly to the pulmonary arteries, was performed. Because of the borderline arterial size and pressure, a 4 $\mathrm{mm}$ fenestration was left in the patched atrial septum. He was extubated on the first postoperative day and maintained an oxygen saturation between 70 and $80 \%$ in air. Fluid retention was minimal. On the 14 th postoperative day he underwent umbrella closure of the fenestration with a $17 \mathrm{~mm}$ ductal umbrella. This was modified by bending each of the arms in its midpoint by roughtly $1 \mathrm{~mm}$, towards the other umbrella (fig 1). This produced some potential overlap of the umbrellas when deployed, so increasing the purchase and stability of the device within the defect. There were no problems with either loading or manipulating the modified device which was deployed after a satisfactory haemodynamic test by balloon occlusion of the atrial septal defect. After the procedure the right atrial pressure increased from 11 to 15 $\mathrm{mm} \mathrm{Hg}$, right atrial saturation increased from $57 \%$ to $74 \%$, and the aortic saturation increased from $78 \%$ to $94 \%$. Angiography showed complete occlusion of the defect (fig 2) with some residual diastolic shunting from the right atrium to the left ventricle through the small ventricular septal defect. He was discharged four days later.

Three more patients underwent closure of the iatrogenic atrial septal defect after the fenestrated Fontan procedure (table 1). These patients had undergone a total cavopulmonary

connection with an intra-atrial baffle connecting the inferior caval vein to the pulmonary artery. The umbrella occlusion technique used, however was the same as that already described. There was no technical difficulty in positioning the modified device. The precision of umbrella placement was greatly enhanced by the use of simultaneous transoesophageal echocardiographic screening. The defect was completely closed in all patients (table 1 ).

CASES 5 AND 6: OCCLUSION OF

\section{AORTOPULMONARY COLLATERALS}

Two patients with pulmonary atresia, ventricular septal defect, and aortopulmonary collaterals remained breathless after successful closure of a ventricular septal defect and placement of a homograft between the right ventricle and the pulmonary artery. Postoperative aortography in the first, an 18 year old female, showed a large aortopulmonary collateral communicating with the right pulmonary artery. There was an hourglass constriction in its midportion (fig 3). With an anterograde arterial approach a $17 \mathrm{~mm}$ ductal umbrella was placed across this stenosis. The second patient, a 21 year old man, also had a large collateral arising from the descending aorta. In his case it communicated with the distal left pulmonary artery, in which there was also a severe proximal stenosis at the insertion of the homograft. Successful balloon dilatation relieved the stenosis completely and was immediately followed by placement of a $12 \mathrm{~mm}$ ductal umbrella in the aortopulmonary collateral (fig 4). The collaterals were completely

Figure 3 Digitally subtracted aortograms from case 5. There is a very large aortopulmonary collateral vessel arising from the descending aorta and supplying the right lung (left hand panel). The right hand panel shows the aortogram after complete occlusion with a $17 \mathrm{~mm}$ umbrella. $A O$, aorta.

Figure 4 Digitally subtracted angiograms from case 6 . The left hand panel shows an injection into the aortopulmonary collateral that is supplying the left lung. There is also a severe stenosis of the pulmonary artery at the distal insertion of the homograft conduit from
the right ventricle (black arrow). The collateral artery was completely occluded with a $12 \mathrm{~mm}$ ductal umbrella (white arrow) after successful balloon dilatation of the pulmonary arterial stenosis (right hand panel). AO, aorta; $A P C$, aortopulmonary collateral; LPA, left pulmonary artery.
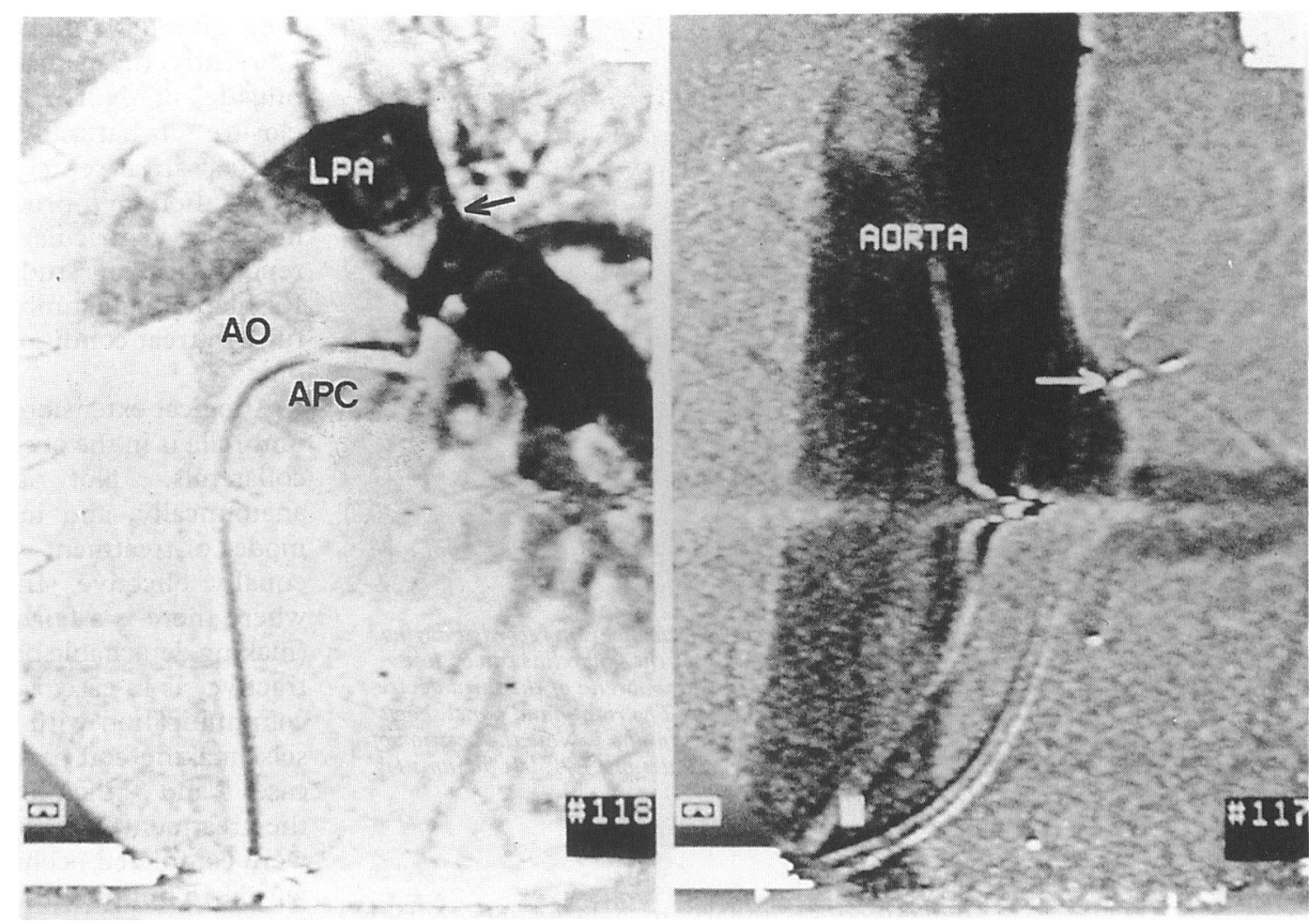

closed in both with resolution of symptoms and no complications.

\section{CASES 7-9: CLOSURE OF VENTRICULAR SEPTAL \\ DEFECT}

Three patients underwent successful placement of umbrella devices in unoperated ventricular septal defects. Table 2 details the diagnosis and haemodynamic data for each of the patients.

Case 7 was a three year old girl, with a diagnosis of situs solitus, a discordant atrioventricular connection and a discordant ventriculoarterial connection. Severe muscular subpulmonary stenosis was treated by placement of a valved homograft between left ventricle and pulmonary artery. Preoperative haemodynamics suggested that her muscular inlet to the ventricular septal defect was severely restrictive (left to right ventricular gradient $=90 \mathrm{~mm} \mathrm{Hg}$ ), and so this was left unoperated. With hindsight, the ventricular septal defect was being occluded by a prolapse of right atrioventricular (mitral) valve tissue into the defect. After relief of the left ventricular outflow tract obstruction the atrioventricular valve tissue was pushed away from the defect, which measured $8 \mathrm{~mm}$ in its largest dimension, resulting in a massive left to right shunt. A total of three $17 \mathrm{~mm}$ umbrellas inserted on separate occasions, were required to lower the pulmonary artery pressure satisfactorily from systemic to near normal levels. The pulmonary to systemic flow ratio fell from roughly 10:1 to $4: 1$ (fig 5). The same method was used on each occasion. The defect was crossed antegradely from a femoral venous approach. An 0.035 inch exchange length guide wire was placed in the right (systemic) ventricle, over which the 11 French long sheath was advanced. The distal umbrella was then deployed and the sheath and device withdrawn towards the defect. The exact position of the umbrella could only be shown with certainty by transoesophageal screening. The proximal umbrella was then positioned so that there was an umbrella on each side of the defect. Transoesophageal Doppler echocardiography was again used to ensure that the device was not interfering with the function of the atrioventricular or semilunar valves before its release (fig 5). Table 2 gives details of the haemodynamic results achieved after each placement.

Two more patients have undergone successful placement of an umbrella device in an unoperated ventricular septal defect. The first was an 18 year old woman with a restrictive perimembranous trabecular ventricular septal defect. She was dyspnoeic on moderate exertion and had an enlarged heart on her chest radiograph. The patient had initially requested surgical closure of the defect. Haemodynamic studies showed that there was a pulmonary to systemic flow ratio of 3.5:1 and the left ventriculogram showed a cone shaped aneurysm of the tricuspid valve around the defect. A $17 \mathrm{~mm}$ umbrella was placed in the defect by the method already described. There was a tiny residual leak shown on the left ventriculogram immediately after closure (fig 6). This was still detectable by Doppler echocardiography four months later, but her symptoms had resolved completely. Follow up at 10 months during the third trimester of an uncomplicated pregnancy showed complete closure.

Case 9 was a five week old infant weighing $3.8 \mathrm{~kg}$ who presented with profound hypoxia and had undergone uncomplicated anatomical correction of transposition of the great arteries on the second day of life. Heart failure 




Figure 5 Left hand panel shows a transoesophageal echocardiogram recorded during placement of the third umbrella device in patient 7. One of the umbrellas can be seen within the ventricular septal defect (arrowed). The distal umbrella of the third device has been positioned and is being pulled towards the defect. The right hand panel shows the radiographic appearance after the third umbrella was in place. Note the position of the transoesophageal echocardiographic probe. $R A$, right atrium; $L A$, left atrium; $L V$, left ventricle; $R V$, right ventricle; $u$, umbrella.

developed secondary to a large left to right shunt through a ventricular septal defect, noted preoperatively but thought to be of little haemodynamic significance. The respiratory rate was in excess of 70 breaths/minute and there had been no weight gain since the operation. The infant had been discharged from hospital on the sixth postoperative day. At cardiac catheterisation there was a pulmonary to systemic flow ratio of $5: 1$ through a $5 \mathrm{~mm}$ perimembranous defect, again partly closed by a cone of tricuspid valve tissue. A $12 \mathrm{~mm}$ umbrella was deployed in the defect. Continuous echocardiographic screening was carried out with a developmental paediatric transoesophageal probe (Hewlett-Packard Instruments). There was an immediate reduction in the pulmonary to systemic blood flow ratio to about $2 \cdot 0: 1$, and considerable symptomatic improvement. Cross sectional echocardiography performed four weeks after the procedure showed a small residual ventricular septal defect and Doppler measurements suggested that the right ventricular systolic pressure was $<40 \mathrm{~mm} \mathrm{Hg}$. She was completely symptom free and thriving.

\section{Discussion}

The use of the Rashkind ductal umbrella and the Lock clamshell device has probably made the biggest impact, in terms of absolute num- bers, on interventional cardiac catheterisation. Currently, the clamshell device is not available outside of North America but successful closure of naturally occurring atrial septal defects ${ }^{1}$ atrial septal defects after the "fenestrated Fontan" procedure, ${ }^{2}$ and unoperated $\underline{\underline{T}}$ muscular ventricular septal defects ${ }^{3}$ has been $\underset{I}{I}$ reported. In our study we have shown that the Rashkind ductal umbrella can be used successfully to treat conditions other than the arterial duct.

A logical extension of the uses of the ductal $\frac{7}{0}$ umbrella is in the occlusion of aortopulmonary collaterals. Not all will be suitable $\frac{\bar{\rho}}{\vec{\sigma}}$ anatomically, and in many cases alternative $\stackrel{\mathbb{D}}{\varrho}$ modes of treatment will be less expensive and equally effective. In those cases, however, $\vec{P}$ where there is a fairly short proximal portion (making detachable balloon embolisation unat- $\vec{\omega}$ tractive, as in case 5), or there is a large distal $\frac{\rho}{\partial}$ communication with the intrapulmonary vessels (making coil occlusion unattractive, as in 8 cases 5 and 6 ) then umbrella occlusion may be $\overrightarrow{.}$ the treatment of first choice. The collaterals were completed occluded in both of our cases 을 within 15 minutes of the umbrella being put in place.

The fenestrated Fontan procedure was described in detail by the Boston group and reflects the increasing trend towards coopera- $\vec{\theta}$ tion between surgeon and cardiologist. ${ }^{2}$ In their $\stackrel{\oplus}{\oplus}$ report, a $17 \mathrm{~mm}$ Lock clam-shell device was used to occlude the iatrogenic fenestration within the atrial baffle in 12 of 20 patients after a modified Fontan procedure. The advantage of the clam-shell device is the double articulation of its arms. This results in an opposing force around the edge of the device so increasing its purchase on the relatively thin atrial septum, or baffle material. This can be similarly achieved with our minor modification of the $17 \mathrm{~mm}$ ductal umbrella. By placing a gentle bend in the arms of each umbrella, the umbrellas overlapped on deployment, thus providing the same effect. Indeed, there was early complete occlusion of the baffle fenestration in all of our patients. We would not, 웅 however, recommend this modification of the device for the application to routine closure of naturally occurring atrial septal defects. It appears that the constant flexion and extension of the arms of the clam-shell device placed in $N$ the normal atrial septum has led to "work hardening" of the arms, resulting in stress fractures in a substantial proportion of cases. The effect of bending the arms of the $17 \mathrm{~mm}$ ductal umbrella is unknown, and it would seem

Table 2 Details of patients 7-9

\begin{tabular}{|c|c|c|c|c|c|c|c|}
\hline Patient & Age & Diagnosis & Device ( $\mathrm{mm}$ ) & $\begin{array}{l}\text { Systolic } \\
P A P / A O P \\
\text { (before) } \mathrm{mm} \mathrm{Hg}\end{array}$ & $\begin{array}{l}\text { Systolic } \\
P A P / A O P \\
\text { (after) } \mathrm{mm} \mathrm{Hg}\end{array}$ & $\begin{array}{l}Q P: Q S \\
\text { (before) }\end{array}$ & $\begin{array}{l}Q P: Q S \\
\text { (after) }\end{array}$ \\
\hline $\begin{array}{l}7 \mathrm{a} \\
7 \mathrm{~b} \\
7 \mathrm{c} \\
8 \\
9\end{array}$ & $\begin{array}{l}\frac{3-6}{\overline{16}-18} \\
5 \text { weeks }\end{array}$ & $\begin{array}{l}\text { A-V discordance, DORV } \\
\text { LV to PA homograft conduit } \\
\text { Muscular VSD } \\
\text { Perimembranous VSD } \\
\text { TGA, perimembranous VSD after TGA }\end{array}$ & $\begin{array}{l}17 \\
17 \\
17 \\
17 \\
12\end{array}$ & $\begin{array}{r}80 / 90 \\
90 / 75 \\
110 / 52 \\
100 / 34 \\
80 / 75\end{array}$ & $\begin{array}{l}\text { NR } \\
95 / 65 \\
110 / 36 \\
110 / 35 \\
80 / 34\end{array}$ & $\begin{array}{l}>10: 1 \\
8: 1 \\
7: 1 \\
3 \cdot 5: 1 \\
6 \cdot 5: 1\end{array}$ & $\begin{array}{l}\text { NR } \\
\text { NR } \\
4: 1 \\
1 \cdot 8: 1 \\
2: 1\end{array}$ \\
\hline
\end{tabular}

A-V, atrioventricular; DORV, double outlet right ventricle; VSD, ventricular septal defect; LV, left ventricle; PA, pulmonary artery; TGA, transposition of the great arteries; PAP/AOP, ratio of pulmonary artery to aortic pressure; QP:QS, pulmonary to systemic flow ratio; NR, not recorded. 
Figure 6 Digitally subtracted left ventriculograms from case 8. The left hand panel shows the conical shaped ventricular septal defect before closure (star). There is only a tiny residual defect after deployment of a $17 \mathrm{~mm}$ umbrella device (right) $L V$, left ventricle.



prudent to defer the elective closure of secundum atrial septal defects until a revised version of the clam-shell device becomes available.

These devices have also been used to occlude postoperative, ${ }^{4}$ and native muscular ventricular septal defects in children before debanding of the pulmonary artery. ${ }^{3}$ The advantage of avoiding ventriculotomy and shortening the period of cardiopulmonary bypass under these circumstances is obvious. Residual leaking around the device was common in the previous reports and was present to some degree immediately after the procedure in all three of our patients in whom a ductal umbrella was used. All were symptomatically improved, however, and cardiopulmonary bypass was avoided in all. It is also possible that complete closure will ultimately evolve (as in case 8), and the procedure has undoubtedly "brought time" for this to occur in the other two. Furthermore, it may be possible to insert further devices to get complete occlusion. For the time being, however, it is a matter of debate as to whether the avoidance of surgery has outweighed the theoretical risks of the now haemodynamically unimportant residual shunting in our patients. There can be no doubt that rigorous attention to bacterial endocarditis prophylaxis will be required.

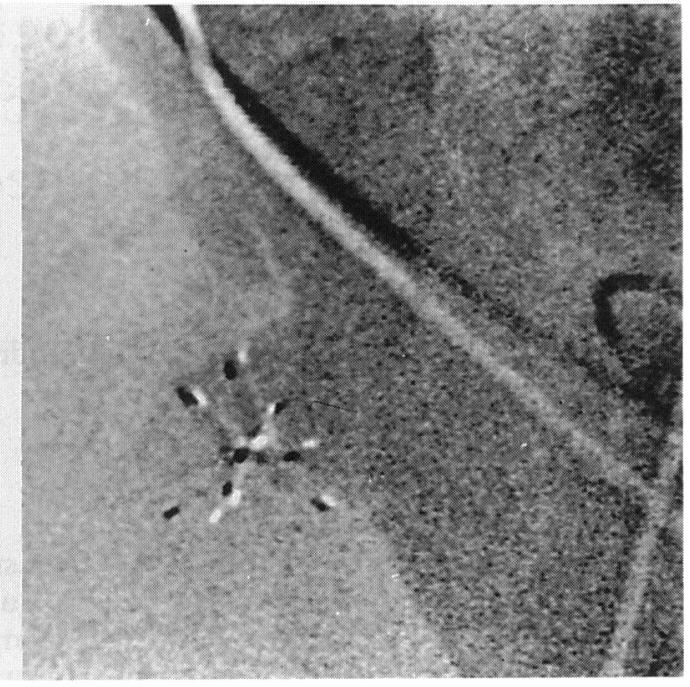

Cases 8 and 9 also show the potential for transcatheter closure of perimembranous ventricular septal defects. When there is tricuspid valve tissue around the defect, the device can be deployed without interfering with either atrioventricular or aortic valve function. We do, however, consider transoesophageal echocardiography to be mandatory in the accurate selection of cases and uncomplicated deployment of the device under these circumstances.

In summary, we have shown that the Rashkind ductal umbrella can be successfully used to treat conditions other than the arterial duct. Transoesophageal echocardiography is an important adjunct to the selection of cases and the successful deployment of the device.

We thank Dr E A Shinebourne and Dr J Somerville for allowing us to study their patients.

1 Rome JJ, Keane JF, Perry SB, Spevak PJ, Lock JE. Doubleumbrella closure of atrial defects: initial clinical applications. Circulation 1990;82:751-8.

2 Bridges ND, Lock JE, Castaneda AR. Baffle fenestration with subsequent transcatheter closure. Circulation 1990; with subseque

3 Bridges ND, Perry SB, Keane JF, et al. Preoperative transcatheter closure of congenital muscular ventricular septal defects. N Engl J Med 1991;324:1312-7.

4 O'Laughlin MP, Mullins CE. Transcatheter closure of ventricular septal defect. Cathet Cardiovasc Diagn 1989; 17:175-9. 